\title{
SOMATOSTATIN CONTENT AND BINDING IN SMALL INIESTINAL MUCOSA FROM FED, FASTED, AND REFED RABBITS
}

B. Roca*, R. Fernandez-Valencia\#, M.N. Rodríguez-Sánchez* and E. Arillia*

Department of * Biochemistry and Molecular Biology and \# Morphological Sciences, Faculty of Medicine, University of Alcalá de Henares, Madrid (Spain)..

(Received in final form September 26, 1990)

\section{Summary}

The present study is an investigation of the effects of 12- to 96-hour's' starvation and 96-hours' starvation plus 48-hour's' refeeding on both somatostatin-like immunoreactivity (SLI) and cytosolic somatostatin binding sites in rabbit small intestinal mucosa. The SLI concentration increased after $24 \mathrm{~h}$ in duodenal and jejunal mucosa, but not in ileal mucosa, and reached its highest value after $96 \mathrm{~h}$ of fasting. The number of specific high and low- af inity somatostatin binding sites, but not their affinity, decreased with the duration of fasting in the same gut segments, refeeding of fasted animals resulted in a return to normal control values for small intestine mucosal SLI and somatostatin binding.

Somatostatin is present in the gut in large amounts in several species including man $(1,2)$. The peptide is found in endocrine cells (D) located in the mucosal layer and the epithelia of gut segments (3), as well as in the neuronal structures of the deep submucosa and muscularis mucosa (4). Juxtaposition of $\mathrm{D}$ cells to certain known target cells for somatostatin is consistent with a local or "paracrine" role for the tetradecapeptide (5). Furthermore, specific somatostatin binding sites have been characterized in the intestinal mucosa $(6-8)$.

A number of studies have shown that somatostatin affects gastrointestinal function and nutrient absorption $(9,10)$. Starvation, a nutrient-deficient state, is known to be associated with an increase of the somatostatin-like immunoreactive (SII) level in the gut $(11,12)$. However, the regulation of intestinal somatostatin binding sites in fasted animals is still unknown. Therefore, in the present study we have investigated somatostatin binding to cytosol in rabbit small intestinal mucosa from animals subjected to shorter or longer pexiods of starvation and in animals which had been fed after fasting. The study also includes the SII concentrations in small rabbit intestinal mucosa in both states.

\section{Materials and Methods}

\section{Chemicals}

Synthetic Tyr ${ }^{11}$-somatostatin and somatostatin-14 were purchased from Universal Biologicals Ltd (Cambridge, U.K., ; aprotinin (Trasylol) was from Bayer (Leverkusen, F.R.G.), trypsin inhibitor and bovine serum albumin were from Sigma (St louis, MO, U., S....) and carrier-free $\mathrm{Na}^{125} \mathrm{I}$ (IMS $30 ; 100 \mathrm{mCi} / \mathrm{m} 1$ ) was from the Radiochenical Centre (Amersham, U.K. .) "This antiserum was raised in rabbits against somatostatin-14 conjugated to bovine serum albumin and is 
specific for somatostatin but, as somatostatin-25 and somatostatin-28, the antiserum does not distinguish between these three forms. All other chemicals were reagent grade.

\section{Experimental animals}

Male rabbits (New Zealand) weighing $1.5-2.0 \mathrm{Kg}$ were divided into three groups: group 1 was fed ad libitum $(n=25)$; group 2 was fasted $12(n=5), 24$ $(n=5), 48(n=5)$, or $96(n=5) \mathrm{h}$; and group 3 had access to food for $48 \mathrm{~h}$ after $96 \mathrm{~h}$ fasting $(\mathrm{n}=5)$. Rabbits were sacrificed by cervical dislocation and gut segments corresponding to the duodenum, jejunum and ileum were immediately
removed.

\section{Binding studies}

Synthetic Tyr ${ }^{11}$-somatostatin was radioiodinated by the method described by Greenwood et al. (13), and purified by chromatography on a Sephadex G-25 column (100 × $1 \mathrm{~cm}$ ) preequilibrated with $0.1 \mathrm{~N}$ acetic acid containing $0.1 \%$ bovine serum albumin. "The specific activity of the purified labelled peptide was determined by the self-displacement method described by Ysewijn-Van Brussel et al. (14) or by the method of Bolton as modified by singh et al. (15). Results obtained by either of the methods were comparable, and for most preparations the specific activity of radioiodinated somatostatin was approxi-
mately $360 \mathrm{Ci} / \mathrm{g}$.

Intestinal mucosa corresponding to the duodenum, jejunum and ileum was incubated at $37^{\circ}$ for $30 \mathrm{~min}$ and then subsequently washed twice in order to remove endogenous somatostatin. The cytosol of intestinal mucosa was isolated according to the method of Reyl-Desmars and Lewin (16). The protein concentration in the cytosol was estimated by the method of Iowry et al. (17) using
bovine serum albumin as a standard.

Experimental conditions for the study of somatostatin binding to the cytosolic fraction of rabbit intestinal mucosa were as previously described (7). Briefly, cytosol from rabbit intestinal mucosa ( $0.2 \mathrm{mg}$ protein/mI) was incubated in $0.5 \mathrm{ml}$ of a medium $(\mathrm{pH} 7.4)$ with the following composition: 0.5 $\mathrm{mM} \mathrm{NaH}_{2} \mathrm{PO}_{4}, 1 \mathrm{mM} \mathrm{CaCl}_{2}, 1_{1} 5 \mathrm{mM} \mathrm{MgCl}_{2}, 50 \mathrm{mM}$ Hepes, $11 \mathrm{mM}$ glucose, $0.1 \%$ bovine serum albumin, $0.1 \mathrm{mg} / \mathrm{ml}$ trypsin inhibitor, and $50 \mathrm{pM} 125 \mathrm{I}$-Tyr $11_{- \text {somatostatin }}$ either alone or together with increasing concentrations of unlabelled somatos-

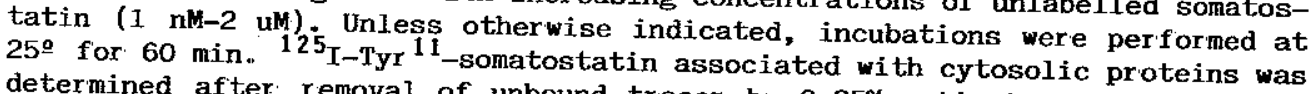
determined after removal of unbound tracer by $0.25 \%$ activated charcoal, $0.5 \%$ bovine serum albumin and $0.025 \%$ T70 dextran $(16,18)$.

The degradation of 125 I-Tyr ${ }^{11}$-somatostatin was assessed by determining the ability of the label remaining in the supernatants of the incubation medium to bind to talc (19). Samples of the supernatants (200 ul) were added to chilled $50 \mathrm{~mm}$ Hepes buffer, pH 7.5, containing $0.25 \%$ human serum albumin (1 mil). After agitation using a vortex mixer, the samples were centrifuged for $10 \mathrm{~min}$ at $4^{\circ}$ and $1700 \mathrm{x} \mathrm{g}$ and the supernatants removed by aspiration. The radioactivity in the pellet and in an aliquot of the original sample (200 ul)

\section{rissue extraction and radioimmunoassay of somatostatin}

Mucosa was dissected free from the muscle layer underlying the duodenum, jejunum and ileum, and immediately boiled for 5 min in $1 \mathrm{~N}$ acetic acid in order to destroy the proteolytic enzymes and coagulate the bulk of the proteins before homogenization (1-2 min) with a motor-driven teflon pestle. This 
procedure does not destroy the ability to detect somatostatin, as Gerich et al. have already shown (20). The homogenate was centrifuged at 3000 r'.p..m. for $30 \mathrm{~min}$ at $4^{\circ} \mathrm{C}$ and the resultant supernatant was stored at $-70^{\circ} \mathrm{C}$ until assay.. Somatostatin concentration was determined by a radioimmunoassay method (20), with a limit of sensitivity of $10 \mathrm{pg} / \mathrm{ml}$.

\section{Statistical analysis}

The statistical evaluation was performed using linear regression analysis and the parametric one-way analysis of variance evaluated by Newman Keuls' multiple comparison procedures. The experiment was performed in triplicate. For Scatchard analysis (21), the stoichiometric binding data were treated with the LIGAND computer program (22).

\section{Results}

With the exception of the ileum, SLI concentration in small intestine mucosa increased after $24 \mathrm{~h}$, and reached its highest level after $96 \mathrm{~h}$ of fasting (Table 1). Two days of refeeding after 96 hours' fasting returned the concentration of duodenal and jejunal mucosal SI I to control values (Table 1).

\section{TABLE 1}

Somatostatin-like immunoreactivity (SLI) concentration in small intestinal mucosa of fed, fasted $(12,24,48$ and $96 \mathrm{~h})$ and refed fasted rabbits.

\begin{tabular}{lcccr}
\hline \multirow{2}{*}{ Groups } & \multicolumn{2}{c}{ SLI concentration (ng/mg protein) } \\
\cline { 2 - 5 } & Duodenum & Jejunum & Ileum & n \\
\hline Fed & $2.11 \pm 0.12$ & $1.52 \pm 0.11$ & $0.87 \pm 0.08$ & 25 \\
12-fast & $2.81 \pm 0.29$ & $1.98 \pm 0.17$ & $0.80 \pm 0.09$ & 5 \\
24-h fast & $4.12 \pm 0.51^{*}$ & $3.25 \pm 0.51^{* *}$ & $0.79 \pm 0.10$ & 5 \\
48-h fast & $5.21 \pm 0.70^{*}$ & $4.55 \pm 0 . .62^{* *}$ & $0.82 \pm 0.07$ & 5 \\
$96-$ h fast & $6.12 \pm 0.91^{*}$ & $5.32 \pm 0.82^{* *}$ & $0.81 \pm 0.08$ & 5 \\
96-h fast plus & & & & \\
48-h refeeding & $2.23 \pm 0.11$ & $1.49 \pm 0.10$ & $0.89 \pm 0.05$ & 5 \\
\hline
\end{tabular}

Statistical comparison versus fed controls: * p $<0.05, *$ p $<0.01$.

The specific binding of ${ }^{125} \mathrm{~T}^{-\mathrm{Tyr}^{11}}{ }^{11}$-somatostatin to cytosol from rabbit small intestinal mucosa from either fed or fasted rabbits depended on time, becoming maximal by $60 \mathrm{~min}$ and then remaining stable for at least another $2 \mathrm{~h}$ in agreement with previous studies (6). All subsequent studies were performed for $60 \mathrm{~min}$ at $25^{\circ} \mathrm{C}$.

The cytosolic preparations from small intestinal mucosa showed a similar extent of somatostatin degradation (between 20 and 25\%) in all the experimental groups and therefore degradation did not depend on fasting time..

The specific binding of ${ }^{125}$ I-Tyr ${ }^{11}$-somatostatin was reversible, since the complex labelled peptide-cytosolic fraction could dissociate upon addition of an excess of unlabelled somatostatin (4 uM) (data not shown). The patterns of dissociation from the cytosolic preparations of fed and fasted rabbits were not significantly different (data not shown). The time by which $50 \%$ of the 
specifically bound ${ }^{125} \mathrm{I}-\mathrm{Ty} \mathrm{r}^{11}$-somatostatin had dissociated from the cytosolic could be established when comparing all the experimental groups.

Increasing concentrations of unlabelled somatostatin competitively inhibited the specific binding of 125 I-Tyr 11 -somatostatin to the cytosolic fraction of intestinal mucosa (Fig. 1).

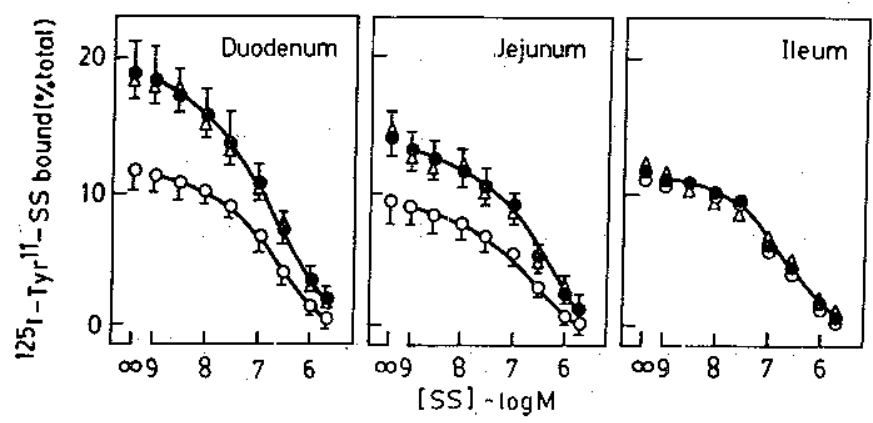

FIG. 1

Competitive displacement of specific ${ }^{125}$ I-Tyr ${ }^{11}$-somatostatin binding to cytosol from rabbit duodenal, jejunal and ileal mucosa by unlabelled somatostatin. Intestinal mucosa cytosol (0.2 mg protein/ml) was incubated with ${ }^{125} \mathrm{I}-\mathrm{Tyr}{ }^{11}$-somatostatin ( $\left.{ }^{125} \mathrm{I}-\mathrm{Tyr}^{11}-\mathrm{SS}, 50 \mathrm{pM}\right)$ at $25^{\circ} \mathrm{C}$ for $60 \mathrm{~min}$ in the absence or presence of increasing concentrations of unlabelled somatostatin. Data correspond to fed $(O), 96 \mathrm{~h}$ fasted $(O)$ and $96 \mathrm{~h}$ fasted plus $48 \mathrm{~h}$ refed $(\triangle)$ rabbits. Each point is the mean of five replicate experiments. Values are expressed as the mean \pm SEM of five replicate experiments. In the ileum SEM are not represented but were always below $10 \%$ of the mean values. For the sake of clarity, intermediate periods are not included, but the corresponding equilibriumbinding parameters are included in rable 2.

Specific binding ${ }^{125}{ }^{\mathrm{I}-\mathrm{Ty}}{ }^{11}$-somatostatin to duodenal and jejunal mucosal cytosol from rabbits fasted more than $12 \mathrm{~h}$ was significantly lower between $24 \mathrm{~h}$ and $96 \mathrm{~h}$, but not after $12 \mathrm{~h}$ of fasting, than that in fed rabbits. However, binding to ileal cytosol did not fall after fasting. Since the observed differences in somatostatin binding may be due to changes in either affinity or capacity of somatostatin binding sites, stoichiometric data were interpreted by the Scatchard method (21). The corresponding Scatchard plots exhibited curvilinear, concave curves that were analyzed on the basis of two classes of somatostatin binding sites (Fig.2) "A least-square regression line was drawn to fit the low affinity sites using the four highest somatostatin concentrations. The contribution of this site was subtracted from the binding obtained at the lowest somatostatin concentrations to obtain the high-affinity binding sites. Table 2 shows the corresponding equilibrium parameters for the high affinity-low capacity and for the low affinity-high capacity sites. The observed differences must be accounted for by a decrease in the number of both classes of somatostatin binding sites in rabbits fasted for 24-96h rather than changes in their affinity. Finally, 48 hour's' refeeding after $96 \mathrm{~h}$ of fasting resulted in binding values that were similar to those in the fed condition. 
TABLE 2

Effects of fasting and refeeding on equilibrium parameters of somatostatin binding to cytosol of rabbit intestinal mucosa.

\begin{tabular}{|c|c|c|c|c|c|c|c|}
\hline \multirow{2}{*}{ Groups } & \multicolumn{2}{|c|}{ Duodenum } & \multicolumn{2}{|c|}{ Jejunum } & \multicolumn{2}{|c|}{ Ileum } & \multirow[b]{2}{*}{$\mathbf{n}$} \\
\hline & $\begin{array}{l}\text { High } \\
\text { affinity }\end{array}$ & $\begin{array}{c}\text { Low } \\
\text { affinity }\end{array}$ & $\begin{array}{l}\text { High } \\
\text { affinity }\end{array}$ & $\begin{array}{c}\text { Low } \\
\text { affinity }\end{array}$ & $\begin{array}{l}\text { High } \\
\text { affinity }\end{array}$ & $\begin{array}{c}\text { Low } \\
\text { affinity }\end{array}$ & \\
\hline \multicolumn{8}{|l|}{ Fed } \\
\hline $\mathrm{Ka}$ & $23.2 \pm 3.5$ & $203 \pm 45$ & $18.8 \pm 2.3$ & $206 \pm 32$ & $18.8 \pm 2.1$ & $194 \pm 12$ & 25 \\
\hline B.c. & $6.1 \pm 0.9$ & $168 \pm 18$ & $2.7 \pm 0.2$ & $138 \pm 18$ & $2.8 \pm 0.3$ & $109 \pm 14$ & \\
\hline \multicolumn{8}{|c|}{ 12-n fasting } \\
\hline Kd & $21.2 \pm 2.5$ & $200 \pm 32$ & $17.2 \pm 2.5$ & $199 \pm 31$ & $18.7 \pm 3.5$ & $198 \pm 13$ & 5 \\
\hline B.C. & $5.9 \pm 1.1$ & $160 \pm 20$ & $2.8 \pm 0.9$ & $137 \pm 20$ & $2.9 \pm 0.6$ & $107 \pm 12$ & \\
\hline \multicolumn{8}{|c|}{ 24-n fasting } \\
\hline Kd & $20.5 \pm 2.7$ & $201 \pm 35$ & $17.5 \pm 2.3$ & $198 \pm 28$ & $18.5 \pm 4.2$ & $197 \pm 12$ & 5 \\
\hline B.c. & $3.8 \pm 1.1 *$ & $120 \pm 13^{*}$ & $1.5 \pm 0.3^{*}$ & $100 \pm 22^{*}$ & $2.5 \pm 0.8$ & $105 \pm 10$ & \\
\hline \multicolumn{8}{|c|}{ 48-h fasting } \\
\hline $\mathrm{Kd}$ & $19.9 \pm 3.5$ & $199 \pm 40$ & $18.2 \pm 2.4$ & $199 \pm 30$ & $19.2 \pm 3.9$ & $199 \pm 13$ & 5 \\
\hline B.c. & $2.8 \pm 0.6 *$ & $101 \pm 14^{*}$ & $0.9 \pm 0.2^{*}$ & $90 \pm 11^{*}$ & $2.4 \pm 0.7$ & $106 \pm 12$ & \\
\hline \multicolumn{8}{|c|}{ 96-n fasting } \\
\hline $\mathrm{Kd}$ & $21.2 \pm 2.3$ & $202 \pm 28$ & $19.5 \pm 2.5$ & $208 \pm 45$ & $20.1 \pm 2.5$ & $210 \pm 10$ & 5 \\
\hline B.c. & $2.3 \pm 0.2^{*}$ & $93 \pm 9^{*}$ & $0.8 \pm 0.1 *$ & $81 \pm 6 *$ & $2.4 \pm 0.6$ & $105 \pm 13$ & \\
\hline \multirow{2}{*}{\multicolumn{8}{|c|}{$\begin{array}{l}96-n \text { fasting plus } \\
48-n \text { refeeding }\end{array}$}} \\
\hline & & & & & & & \\
\hline $\mathrm{Kd}$ & $20.5 \pm 4.2$ & $203 \pm 35$ & $19.7 \pm 3.2$ & $205 \pm 35$ & $19.5 \pm 4.1$ & $195 \pm 11$ & 5 \\
\hline B.c. & $5.9 \pm 1.2$ & $166 \pm 20$ & $2.6 \pm 0.7$ & $140 \pm 25$ & $2.8 \pm 0.7$ & $110 \pm 15$ & \\
\hline
\end{tabular}

Values were obtained by Scatchard analysis (19) of data from Fig.2. Kd is the dissociation constant, nM; B.c. 1s the binding capacity, pmol somatostatin bound/mg protein. Mean values \pm S.E.M. Statistical significance: ${ }^{*}$ p<0.05 vs control value. 


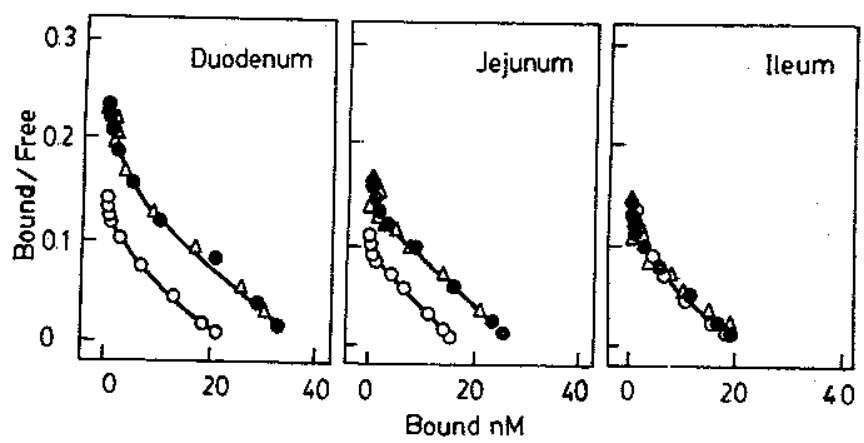

FIG. 2

Scatchard plots of somatostatin binding to rabbit cytosolic fraction of duodenal, jejunal and ileal mucosa. Points were calculated from the mean values given in Fig, 1 and correspond to fed (O), $96 \mathrm{~h}$ fasted $(O)$ and plus $48 \mathrm{~h}$ refed $(\Delta)$ rabbits.

\section{$\underline{\text { Discussion }}$}

The present study indicates that duodenal and jejunal mucosal SLI concentrations increased in fasted rabbits after $24 \mathrm{~h}$, whereas the number of both high- and low-affinity somatostatin binding sites decreased (without changes in the affinity values) in the cytosol from mucosa of both intestinal segments, as compared to control conditions. Refeeding of fasted animals resulted in a normalization to the control values of small intestine mucosal SII and somatostatin binding .

125 Conlon et al. (19) have demionstrated that the rate of degradation of is similar to that of sos measured by the loss of ability to bind to talc, of somatostatin reas relatively important but it reached similar values in all the experimental groups, so it was possible to compare their type values. The values calculated for Kd and binding can be modified by ${ }^{125}{ }_{1-T y r}{ }^{11}$-somatostatin degradation and so they must be considered as apparent.

Starvation-induced SII increases in duodenal and jejunal mucosa have previously been reported in normal animals $(12,23)$. Whether this increase in SLI reflects decreased release of SLI into the circulation, increase biosynthesis, or decreased degradation can not be answered at this time..

We were unable to demonstrate specific somatostatin binding in isolated cell membranes from rabbit small intestinal mucosa in variety of experimental conditions tested. Intracellular somatostatin binding sites were first described by Ogawa et al. (18). They suggested that the somatostatin binding protein is an easily soluble membrane protein. Recently, it has been demonstrated that somatostatin binding sites exist in secretion vesicles (24), homogenization of tissues can expose the total pool of cellular somatostatin binding sites, from both the plasma membrane and the secretion vesicle fraction (25). It is likely 
that the secretory vesicles function as a depot or reservoir for internalized membranes binding sites (26). Another possibility is that the vesicles may be involved in the intracellular transport of newly synthesized somatostatin binding sites between the Golgi complex and cell membranes (24). The presence of somatostatin binding sites at the site of fusion between the secretion vesicle and the plasma membranes may represent an important aspect of its overall inhibitory effect on polypeptide hormone secretion (27). In anterior. pituitary cells, intracellular binding sites are biologically active before they are inserted into the plasma membranes (28).

In both the pancreas and gastric mucosa, the cytosolic sites were substan tially denser than the membrane sites, and showed a lower apparent affinity than did membrane sites (16). Such comparison could, however, be biased by the possible presence of additional low affinity sites.

Evidence that somatostatin can penetrate plasma membrane in vitro is supported by previous binding studies on isolated rat gastric mucosal cells (29) and in primary culture of rat anterior pituitary cells (30). The process by which such a penetration would occur is unknown so far but it may be tentatively suggested that it involves internalization of surface binding sites, as proposed for insulin (31). The intracellular binding sites for somatostatin in a number of tissues including the small intestinal mucosa may behave as a phosphoprotein phosphatase regulatory subunit and therefore somatostatin could lead to the corresponding physiological effects (32).

The affinities of the two classes of binding sites are comparable to those reported in previous studies on somatostatin binding to the cytosol from chicken pancreas (33), rat small intestinal epithelium (6), and human placental membranes (34). In this context, the $K d$ values of the high affinity sites approach the somatostatin concentration that can act on sodium and chloride absorption in rabbit intestine (35) and which affects growth and differentiation in cultured rabbit intestinal mucosa (36). However, somatostatin bound with a higher affinity to the cytosolic fraction of both rat pancreas and gastric mucosa (16) and rat brain membranes (37). Present affinity values are not compatible with the low circulating levels of the peptide. However, the presence of somatostatin in both paracrine cells (3) and nerve ending (4) in the intestinal mucosa may make local concentration of somatostatin high enough to interact with the reported binding sites.

The mechanism that alters the number of somatostatin binding sites is not known. The observed high levels of intestinal somatostatin could result in a much increased local somatostatin release. In general, if the release of ligand increases, the number of receptors for the ligand decreases over time by down-regulation (38) and we did detect a decrease of somatostatin binding sites. In this regard, recent data has indicated that hypothalamic somatostatin release causes a reduction in the number of somatostatin binding sites in rat pituitary membranes (39). It has also been shown that preincubation of pituitary tumor cells with somatostatin results in a marked decrease of the number of somatostatin binding sites (40). One explanation for the loss of binding sites might be persistent binding-site occupancy by the hormone., However, almost complete dissociation specific somatostatin binding can be found following incubation at $37^{\circ}$ for 30 min as previously described (41). Therefore, it seems unlikely that the reduction in apparent binding site density was due to persistent binding site occupancy."

The significance of the decrease in somatostatin binding to cytosol from small intestine mucosa after fasting remains unclear, since the role of altered binding site capacity in modulating the effects of intestinal somatostatin has not been evaluated. 


\section{Acknowledgements}

The authors are greatly indebted to Professor J.C. Prieto for useful criticism, and to Professor. I. Gomez Pellico for his encouragement and support throughout this study. This work was supported by grants from the Comision Interministerial de Ciencia y Tecnologia (PB87/0753) and the Fondo de Investigaciones Sanitarias de la Seguridad Social (88/0903) of Spain. The authors thank Carol F, Warren, from the Alcalá de Henares University Institute of
Education Sciences for her editorial help.

\section{References}

1. C. MC INTOSH, R. ARNOL.D, E. BOTHE, H. BECKER, J. KOBBERI ING and CREUTZFELDT, Gut 19 655-663 (1979).

2. E. PENMAN, J....J. WASS, M.G. BUTLER, E..S , PENNY, J. PRICE, P. WU and I.H.. REES, Regul.. Peptides $7 \underline{7} 53-65$ (1983).

3. J. ALUMETS, F". SUNDLER and T. HAKANSON, Cell Tissue Res. 185 (1977).

4. R, HOKFELZT, I . G. ELFVIN, R. ELDE, M. SCHULTXBERG, M. GOLDSIEIN and R. LUF T, Proc. Nat, Acad. Sci, U..S..A. 74 3587-3591 (1977).

5. L. I. LARSSON, Gut hormones, pp. 350-353, S.R., Bloom and J.M. Polak, Churchil-Livingstone, Edinburgh (1981).

6. E. ARILLA, M.P. LOPEZ-RUIZ, L. GONZALEZ-GUIJARRO, J.C. PRIEI -PAN and B.H. HIRST, Biochín

7. L.G. GUIJARRO, F. ARTLLA M.P Bophys. Acta 802 203-208 (1984).

B..H. HIRST, Regul " Peptides $10207-215$ (1985) .C. PRIETO; C. WHITFORD and

8. M. WEBER, T . COLE

9. V. SCHUSDZIARRA, V. HARRIS, A.ON, Am. J. Physiol. 205 G679-G685 (1986). 1705-1708 (1979).

10. V. SCHUSDZIARRA, E. ZYZNAR, D. ROUIL LER, G. BODEN, J C BROWN, A. ARIMU and R.H. UNGER, Science 207 530-532 (1980).

11. B SHAPIRO

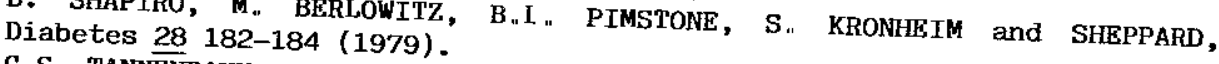
12. G.S. TANNENBAUM, $O$. FORSTAD and $P$, BRAZEAU, Endocr.inology 104 1733-1738
(1979).

13. F.C. GREENWOOD, W.M. HUNTER and I.S. GLOWER, Biocher. $J_{\text {" }}^{89}$ 114-123

14. K.A.R.N. YSEWIJIN-VAN BRUSSEL, A.C. VAN STEIRIEGHEM and A.P. DE IEENHEER,

J. Labelled Compd." Radiopharm. 20 89-99 (1983). 15. P. SINGH, B. RAE-VENTER, C.M. J J. TOWNSEND, T. KHAIII and $J_{\text {.. }}$ " THOMPSON,
Am. J " Physiol. 249 G761-G769 (1985).

16. R. REYL-DESMARS and M.J.M. LEWIN, Biochem, Biophys. Res. Commun. 109 17. O.H. LOWRY, R...” ROSEBROUGH, A.I. FARR and R..J. RANDALL, J " Biol. Chem .
193 265-275 (1982).

18. N. OGAWA, T. THOMPSON and H.G. FRIESEN, Biochem. J. 165 269-277 (1977).

19. J.M. CONION, J. WHITTAKER, V. HAMMOND and K.G.M. M. ALBERTI, Biochim.

20. J. GERICH, K. 677 234-242 (1981).

93 1009-1017 (1979)

21.

22. P. MUNSON and Ann. N.Y. Acad. Sci. 51 660-672 (1949).

23. A. SHULKES, U. CAUSSIGNAC, Anal. Biochem. 107 220-239 (1980).

A. SHULKES, U. CAUSSIGNAC, C..B. IAMERS, T.E. SOLOMON, I. YAMADA and J."H. WALSH, Austr. J. Exp. Biol. Med. Sci" 61 Pt5 581-587 (1983).

24. B. DRAZNIN, P. MEHLER, J..W. LETTNER, K.E. SUSSMAN, R. DAHL, A. VATTER and S. MEL MED, J. Receptor Res. 5 83-103 (1985).

25. K.E. SUSSMAN, B. DRAZNIN, J.W. LEIPNER and P..S. MEHLER, Metabolism 31 
26. G. MOREL , G. PELLETIER and S. HEISI ER, Endocrinology 119 1972-1979 (1986) .

27. B. DRAZNIN, C. STEINER, N. SHERMAN and K. SUSSMAN, Biochem. Biophys . Res. Commun. 139 673-678 (1986).

28. C. STEINER, R. DAHI, N. SHERMAN, M. TROWBRIDGE, A. VATTER, R. ROBBINS and B. DRAZNIN, Endocrinology 118 '766-'777 (1986).

29. F. REYL, C. SILVE and M., ..M. IEWIN, Hormone receptors in digestion and nutrition, pp. 391-400, G. Rosselin et al" (eds.), Elsevier-North Holland, Amsterdam (1979).

30. B. DRAZNIN, J, SHERMAN, $K$, SUSSMAN, R. DAHI and A.. VATTER, Endocrinology 117 960-966 (1985).

31. J. SCHIESSINGER, Y. SHECHTER, M.C. WILLINGHAM and I. PASTAN, Proc. Natl., Acad. Sci. USA, 75 2659-2663 (1978).

32. F..J. REYI and M.J.M. LEWIN, Proc. Nat. Acad. Sci. USA 76 978-982 (1982).

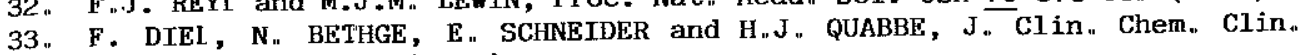
Biochem. 19 99-107 (1981).

34. E. TSAI IKAN, T.,P. FOLEY and D.J. BECKER, Pediat. Res. 18 953-95'7 (1984).

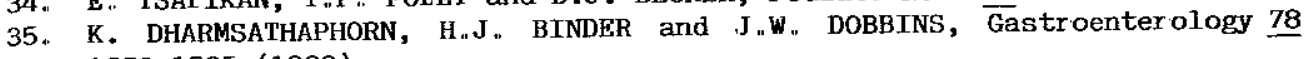
1559-1565 (1980).

36. F. .E. STANGE, A. SCHNEIDER, V. SCHUSDZTARRA and H. DITSCHUNETT, Horm。 Metab. Res. 16 74-78 (1984).

37. J. EPELBAUM, L. TAPIA-ARANCIBIA, C. KORDON and A. ENJALBERT, J "Neur ochem., 381515-1523 (1982).

38. B.I. POSNER, M.N. KHAN and J.J. BERGERON, Pediatric Endocrinology pp., 29-61, R. Collu (ed.), Raven Press, New York (1981).

39. H. KATAKAMI, M. BERELOWITZ, M. MARBACH and I "H. FROHMAN, Endrocrinology 117 557-560 (1985).

40. $\overline{C . S}$. SRIKANI and S. HEISIER, Endocrinology 117 271-178 (1985).

41 . T. HIGUCHI, T. KOKUBU, G.S. SIKAND, J.A. WADA and H.G. FRIESEN, $J$. Neurochem. 43 1271-1276 (1984). 